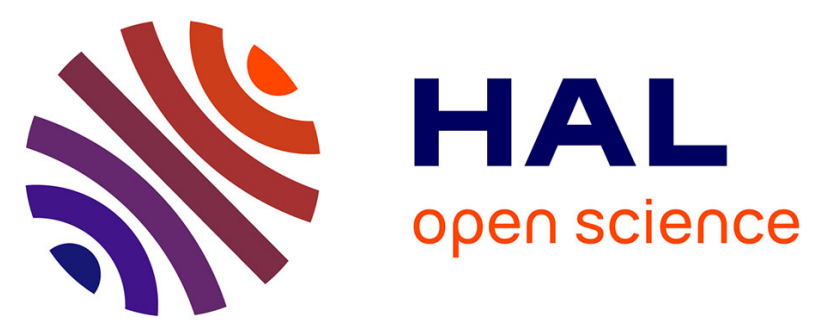

\title{
Inferring transit time distributions from atmospheric tracer data: Assessment of the predictive capacities of Lumped Parameter Models on a 3D crystalline aquifer model
}

Jean Marçais, Jean-Raynald de Dreuzy, Timothy R. Ginn, Pauline Rousseau Gueutin, Sarah Leray

\section{To cite this version:}

Jean Marçais, Jean-Raynald de Dreuzy, Timothy R. Ginn, Pauline Rousseau Gueutin, Sarah Leray. Inferring transit time distributions from atmospheric tracer data: Assessment of the predictive capacities of Lumped Parameter Models on a 3D crystalline aquifer model. Journal of Environmental Hydrology, 2015, 525, pp.619-631. 10.1016/j.jhydrol.2015.03.055 . insu-01140661

\section{HAL Id: insu-01140661 \\ https://hal-insu.archives-ouvertes.fr/insu-01140661}

Submitted on 9 Apr 2015

HAL is a multi-disciplinary open access archive for the deposit and dissemination of scientific research documents, whether they are published or not. The documents may come from teaching and research institutions in France or abroad, or from public or private research centers.
L'archive ouverte pluridisciplinaire HAL, est destinée au dépôt et à la diffusion de documents scientifiques de niveau recherche, publiés ou non, émanant des établissements d'enseignement et de recherche français ou étrangers, des laboratoires publics ou privés. 
INFERRING TRANSIT TIME DISTRIBUTIONS FROM ATMOSPHERIC TRACER DATA: ASSESSMENT OF THE PREDICTIVE CAPACITIES OF Lumped Parameter Models on A 3D CRYSTAlline AQUifer MOdel

\author{
J. Marçais ${ }^{1 \mathrm{a}, \mathrm{b}}$, J.-R. de Dreuzy ${ }^{\mathrm{b}}$, T. R. Ginn ${ }^{\mathrm{c}}$, P. Rousseau-Gueutin ${ }^{\mathrm{d}}$, S. \\ Leray $^{\mathrm{e}}$ \\ ${ }^{a}$ Géosciences Rennes (UMR 6118 CNRS), Université de Rennes 1, Campus de Beaulieu, \\ 35042 Rennes Cedex, France \\ ${ }^{b}$ Agroparistech, 16 rue Claude Bernard, 75005 Paris, France \\ ${ }^{c}$ University of California, Department of Civil and Environmental Engineering, 1 Shields \\ Avenue, Davis, CA 95616, USA \\ ${ }^{d}$ EHESP Rennes, Sorbonne Paris Cité, Paris, France \\ ${ }^{e}$ IFP Energies nouvelles, 1 - 4 avenue de Bois-Préau, 92852 Rueil-Malmaison Cedex, \\ France
}

\title{
Abstract
}

While central in groundwater resources and contaminant fate, Transit Time Distributions (TTDs) are never directly accessible from field measurements but always deduced from a combination of tracer data and more or less involved models. We evaluate the predictive capabilities of approximate distributions (Lumped Parameter Models abbreviated as LPMs) instead of fully developed aquifer models. We develop a generic assessment methodology based on synthetic aquifer models to establish references for observable quantities as tracer concentrations and prediction targets as groundwater renewal times. Candidate LPMs are calibrated on the observable tracer concentrations and used to infer renewal time predictions, which are compared with

\footnotetext{
${ }^{1}$ Corresponding author. Phone: + 33173716144 .

Email adress: jean.marcais@polytechnique.edu
} 
the reference ones. This methodology is applied to the produced crystalline aquifer of Plœmeur (Brittany, France) where flows leak through a micaschists aquitard to reach a sloping aquifer where they radially converge to the producing well, issuing broad rather than multi-modal TTDs. One, two and three parameters LPMs were calibrated to a corresponding number of simulated reference anthropogenic tracer concentrations (CFC- $11,{ }^{85} \mathrm{Kr}$ and $\mathrm{SF}_{6}$ ). Extensive statistical analysis over the aquifer shows that a good fit of the anthropogenic tracer concentrations is neither a necessary nor a sufficient condition to reach acceptable predictive capability. Prediction accuracy is however strongly conditioned by the use of a priori relevant LPMs. Only adequate LPM shapes yield unbiased estimations. In the case of Plomeur, relevant LPMs should have two parameters to capture the mean and the standard deviation of the residence times and cover the first few decades $[0 ; 50$ years]. Inverse Gaussian and shifted exponential performed equally well for the wide variety of the reference TTDs from strongly peaked in recharge zones where flows are diverging to broadly distributed in more converging zones. When using two sufficiently different atmospheric tracers like CFC-11 and ${ }^{85} \mathrm{Kr}$, groundwater renewal time predictions are accurate at 1 to 5 years for estimating mean transit times of some decades (10-50 years). 1-parameter LPMs calibrated on a single atmospheric tracer lead to substantially larger errors of the order of 10 years, while 3-parameter LPMs calibrated with a third atmospheric tracers $\left(\mathrm{SF}_{6}\right)$ do not improve the prediction capabilities. Based on a specific site, this study highlights the high predictive capacities 
of two atmospheric tracers on the same time range with sufficiently different atmospheric concentration chronicles.

Keywords: Transit time distributions, Lumped parameter models, Renewal times, Atmospheric anthropogenic tracers, Crystalline aquifer

\section{Introduction}

Transit times in groundwater flow systems result from local-scale advective and dispersive processes (Bellin \& Tonina, 2007; Dagan et al., 1992; Dentz, 2012; Maloszewski \& Zuber, 1996; Simmons, 1982), as well as from 5 global-scale watershed and geological structures (Eberts et al., 2012; Goderniaux et al., 2013; McGuire \& McDonnell, 2006; Rinaldo et al., 2011). Hence Transit Time Distributions (TTDs) are most generally broad, mixing times of different flow lines (Engdahl \& Maxwell, 2014; Ginn, 1999) potentially acquired from various recharge areas (Weissmann et al., 2002), within a succession of aquifers and aquitards (Castro \& Goblet, 2005; Phillips \& Castro, 2003; Zinn \& Konikow, 2007), or through exchanges between high-flow zones like fractures and large diffusive zones like the matrix (Cook et al., 2005; Haggerty \& Gorelick, 1995; Varni \& Carrera, 1998). With only scarce observations, it is out of reach to identify accurately which processes intervene where and how multiscale complexity of the flow structures generate the TTD. Nevertheless some characteristics of the TTD, also called "groundwater age distribution" (Ginn, 1999) or "groundwater residence time distribution" (McCallum et al., 2014a) may be inferred from measurements of isotopic tracer concentrations in the groundwater (McCallum et al., 2014b; Massoudieh et al., 2012; Massoudieh \& Ginn, 2011; Newman et al., 2010). 
We refer to these data as "groundwater age data." Moreover classical renewal and flushing time applications can directly be derived from the TTD without going back to the transport processes (Bohlke, 2002; Katz et al., 2001; Lerner \& Papatolios, 1993; Pinay et al., 2014; Sebilo et al., 2013).

In this framework the model for the TTD takes the critical role of translating groundwater age data to renewal or flushing predictions, that with any principle of parsimony should be simple enough to be fully determined by the scarce information available. It should also be representative in a broad sense of the underlying transport processes. This has promoted the development of simple TTD models known as Lumped Parameter Models (LPMs) that represent the multi-scale multi-factor dispersive processes all together in a parsimonious "lumped" way (Cook \& Herczeg, 2000; Maloszewski \& Zuber, 1996). Numerous LPMs have been proposed following different primary objectives. Some have been developed to efficiently fit observed groundwater ages like the mono- or multi-modal Dirac distributions corresponding to one or several piston flow models (Begemann \& Libby, 1957), or flexible generalized Gamma distributions (Cvetkovic, 2012). Others are analytical solutions of simplified problems. This is the case of the Inverse Gaussian distribution solution to the 1D advection-dispersion equation (Ginn et al., 2009), of the exponential model taken from chemistry of continuous stirred tank reactors (Eriksson, 1958; Haitjema, 1995; Kaufman \& Libby, 1954), and of some more complex semi-analytical distributions for gently sloping aquifers (Etcheverry \& Perrochet, 2000) or dipole flow configurations (Luo \& Kitanidis, 2004). Increasing their complexity to three or more parameters has been proposed by 45 composing some of the previous distributions (Ozyurt \& Bayari, 2003, 2005). 
Globally, LPMs have been proposed following Bayes spirit either by favoring the goodness of fit of the groundwater ages (likelihood in Bayes theory) like for the multi-modal Dirac distributions, or by favoring some consistency with the a priori flow pattern (prior in Bayes theory) such as for the Inverse Gaussian or exponential models. LPMs are still extending to "shape-free" distributions precisely designed to find an optimal balance of the likelihood and prior terms within a Bayesian framework (Massoudieh et al., 2012, 2013).

Lumped Parameter Models are highly attractive as they offer predictive capacities at limited observation and modeling costs. However, they raise a number of questions that should be carefully assessed: is the LPM approach appropriate for 3D complex aquifers? How should the LPM distribution be chosen? Is there any a priori more relevant LPM among the existing analytical solutions? When is the information content of the groundwater age data enough for establishing the targeted predictions like the renewal or flushing times?

Assessment studies have been undertaken on sampling zones located preferentially in the downstream convergence zones (Eberts et al., 2012; Leray et al., 2012), using extensively geographical information with simple transport solutions (Basu et al., 2012), or with two parameters widely varying LPMs under a broad panel of observation and tracer scenarios (Green et al., 2014). In this article, we analyze the predictive capacities of LPMs against evolving quantity of tracer information. We adapt the LPM complexity through the number of its parameters to the informational content of the tracer data, in order to determine the relation between the informational 70 content of the tracer data and the quality of the predictions. While our 
analysis is centered on LPMs, LPMs just appear as the necessary step to extract from the tracer data the information needed to establish predictions. We first propose a methodology for a spatially extensive assessment of the LPMs (section 2). It is illustrated on a 3D crystalline aquifer model under steady-state convergent flow (section 3). Seven LPMs are compared at 73 locations of the crystalline aquifers (section 4). Results are further discussed in section 5 to determine the quantity of information required to establish accurate renewal time predictions.

\section{Methodology: assessing LPMs on in-silico aquifers}

We detail the methods for determining the predictive capacities of Lumped Parameter Models (LPMs) based on groundwater age information derived from tracer concentrations on in-silico aquifers. In-silico aquifers, also generally called synthetic aquifer models, are essential since the assessment procedure requires the knowledge of the true Transit Time Distributions (TTDs). As TTDs cannot be obtained in the field from any measurement at the watershed scale, we access it through aquifer modeling. Both 2D and 3D theoretical models have brought up key issues (Massoudieh et al., 2012; Park et al., 2002; Varni \& Carrera, 1998; Weissmann et al., 2002; Zhang, 2004; Zinn \& Konikow, 2007), as has direct modeling of age distributions in real 2D aquifer case (Woolfenden \& Ginn, 2009). The most relevant aquifer models are however those closer to the 3D real aquifer cases calibrated using both hydraulic and atmospheric tracer information (Eberts et al., 2012; Green et al., 2014; Leray et al., 2013).

In this section, we assume that transport simulations have previously been 
performed and that the necessary results are available. These results can take the form of particle paths or concentration fields depending on the numerical method chosen for solving the advective-dispersive equation (Bear, 1973). When using random walk methods (Delay et al., 2005; Kinzelbach, 1988; Tompson \& Gelhar, 1990), results are particle paths derived from forward or backward simulations (Neupauer \& Wilson, 2002). For a straightforward derivation of concentrations from particle densities under forward tracking, particles must be injected at densities proportional to the inflow boundary fluxes. In recharge and pumping cases, the density of injected particles must be weighted by flows entering the aquifer either by the recharge zones in forward studies or by the sampling areas in backward studies (Leray et al., 2012). The method is general in the sense that it can be applied to any aquifer model with adequate transport simulation and injection conditions. In this article, it will be applied to the crystalline aquifer model of Plœemeur described in section 3. We discuss application to other sites in section 5 . Methods are organized in 5 steps. In the two first steps, the transit time distributions (TTDs) are used to establish the reference atmospheric tracer concentrations often displayed as groundwater ages and the reference predictions. The third step consists in defining the candidate LPMs. Several LPMs are concurrently considered. In this article, we consider seven LPMs with evolving number of parameters. This is a key point of our methodology for studying the evolution of the prediction capacities according to the quantity of available information in the atmospheric tracer concentrations. The number of informative parameters will be taken as a measure of the available information. We then calibrate the LPMs on the reference atmospheric 

obtained are the references to which will be compared the approximations obtained with LPMs.

From the TTDs, we derive the reference tracer concentrations $C_{\mathrm{Tr}}^{\mathrm{ref}}$. For a 
given time and position $(t, \mathbf{x})$ these concentrations can be readily expressed from the TTD $f_{\text {ref }}$ determined previously, the atmospheric concentration chronicle of the tracer $\mathscr{C}_{\operatorname{Tr}}$ and its possible decay constant $\lambda$ :

$$
C_{\operatorname{Tr}}(t, \mathbf{x})=\int_{0}^{t} \mathscr{C}_{\operatorname{Tr}}(t-u) e^{-\lambda u} f_{\text {ref }}(u, \mathbf{x}) \mathrm{d} u
$$

where $t-u$ is the date when the tracer enters the aquifer. $C_{\mathrm{Tr}}^{\mathrm{ref}}$ corresponds to

the concentration $C_{\operatorname{Tr}}(t, \mathbf{x})$ at a given sampling date $t$ and at the position $\mathbf{x}$. These concentrations computed for different environmental tracers such as CFC-11, $\mathrm{SF}_{6}$ and ${ }^{85} \mathrm{Kr}$ (see Figure 1) are taken as observables. They closely match sampled concentrations in field studies.

The concentrations can readily be converted to apparent ages $\hat{A}_{\mathrm{Tr}}$ :

$$
C_{\operatorname{Tr}}(t, \mathbf{x})=\mathscr{C}_{\operatorname{Tr}}\left(\hat{A}_{\operatorname{Tr}}(t, \mathbf{x})\right) e^{-\lambda \hat{A}_{\operatorname{Tr}}(t, \mathbf{x})}
$$

Tracers are considered ideal, i.e. they do not have any interaction with the aquifer matrix (Maloszewski \& Zuber, 1996). We also assume that tracers are at their atmospheric concentration at the aquifer recharge $\mathscr{C}_{\operatorname{Tr}}$ (equations 1 and 2)

\subsubsection{Reference predictions}

From the reference TTDs $f_{\text {ref }}$ we also derive renewal times in the aquifer. For a given sampling zone, the renewal period $t_{y}$ of a fraction $y$ of the water to be renewed in aquifer is defined as

$$
y=F_{\text {ref }}\left(t_{y}\right)=\int_{0}^{t_{y}} f_{\text {ref }}(u) \mathrm{d} u
$$


where $F_{\text {ref }}$ is the cumulative density function. The quartiles $Q_{1}^{\text {ref }}$ (resp. $Q_{2}^{\text {ref }}$ opposed to the approach of Corcho Alvarado et al. (2007), the number of degrees of freedom is always equal to 0 as the number of free parameters is made equal to the number of observations.

We choose seven LPMs that either correspond to prior information on the flow pattern or that are often used in hydrogeological studies. We sort them according to the number of parameters required to define them (see table 1) and detail in the following their physical basis. They are all defined only for 
$t \geqslant 0$.

We have chosen the Dirac and exponential distributions as 1-parameter models. Physically, the Dirac distribution corresponds to the piston flow model (PFM), where tracers are advected along a single flowpath without any mixing within the flow line nor with the other flow lines. At the other extreme, the exponential model (EM) characterizes a well-mixed flow and is relevant to TTDs at convergent and outflow zones (pumping site, discharge). Both distributions are defined by a single parameter $T$ equal in both cases to their mean.

A straightforward extension to 2-parameter models is the Shifted Exponential distribution corresponding to the exponential piston flow model (EPM) and representing a combination of exponential and piston flow models. Such a distribution can represent a system where recharge occurs in an unconfined zone (EM) and tracers are then advected in a confined part of the aquifer $(\mathrm{PFM})$. It is defined by the same exponential constant $T$ and by the time lag $t_{0}$. The other classical 2-parameter model is the Inverse Gaussian distribution. It is a solution to the classical advection dispersion equation (ADE) and is characterized by the distribution mean $T$ and by the Peclet number Pe (Maloszewski \& Zuber, 1996). Pe is related to macrodispersive watershed processes with potentially much smaller values than classical microscale hydrodynamic dispersion. The lower $P e$ is, the broader and the more asymmetrical the TTD will be. The last 2-parameter model considered 200 is the uniform distribution corresponding to the linear piston flow model, which can represent the TTD in a partly confined aquifer (Cook \& Bohlke, 1999). It is characterized by the two extreme times $t_{0}$ and $t_{1}$. 
As 3-parameter models, we have taken the weighted sum of two Diracs typically used in karstic systems (Long \& Putnam, 2006) or when considertion. In fact the more different the atmospheric concentration chronicles, the more complementary information can be extracted.

1-parameter LPMs are calibrated on the reference CFC-11 tracer concentration $\left(C_{\mathrm{CFC}}^{\mathrm{ref}}\right)$. 2-parameter LPMs are calibrated on the reference CFC-11 225 and ${ }^{85} \mathrm{Kr}$ tracer concentrations $\left(C_{\mathrm{CFC}}^{\mathrm{ref}}\right.$ and $\left.C_{\mathrm{Kr}}^{\mathrm{ref}}\right)$. 3-parameter LPMs are calibrated on the reference $\mathrm{CFC}-11,{ }^{85} \mathrm{Kr}$ and $\mathrm{SF}_{6}$ tracer concentrations $\left(C_{\mathrm{CFC}}^{\mathrm{ref}}\right.$, $C_{\mathrm{Kr}}^{\mathrm{ref}}$ and $\left.C_{\mathrm{SF}_{6}}^{\mathrm{ref}}\right)$. 
For each N-parameter LPM (where N equals either 1, 2 or 3) we seek for the parameters $\left(\pi_{1}, \cdots, \pi_{\mathrm{N}}\right)$ that solve the system of $\mathrm{N}$ equations:

$$
\text { For } n=1 \cdots N, C_{\operatorname{Tr}_{n}}^{\mathrm{ref}}=\int_{0}^{t} \mathscr{C}_{\operatorname{Tr}_{n}}(t-u) f_{\left(\pi_{1}, \cdots, \pi_{\mathrm{N}}\right)}(u) \mathrm{d} u
$$

where $\mathrm{N}$ is the number of parameters and $\operatorname{Tr}_{n}$ is the nth tracer (if $n=1, \operatorname{Tr}_{1}$ is CFC-11, if $n=2, \operatorname{Tr}_{2}$ is ${ }^{85} \mathrm{Kr}$ and if $n=3, \operatorname{Tr}_{3}$ is $\mathrm{SF}_{6}$ ).

We use the Levenberg-Marquadt method of Matlab to find the set of parameters $\left(\pi_{1}, \cdots, \pi_{n}\right)$ that minimize the objective function $\chi$ :

$$
\chi=\sum_{n=1}^{\mathrm{N}}\left|\frac{\nu_{n}\left(\pi_{1}, \cdots, \pi_{\mathrm{N}}\right)}{C_{\operatorname{Tr}_{n}}^{\mathrm{ref}}}\right|^{2}
$$

where:

$$
\nu_{n}=C_{\operatorname{Tr}_{n}}^{\mathrm{ref}}(t)-\int_{0}^{t} \mathscr{C}_{\operatorname{Tr}_{n}}(t-u) f_{\left(\pi_{1}, \cdots, \pi_{\mathrm{N}}\right)}(u) \mathrm{d} u .
$$
gorithm not far from the global minimum of the objective function $\chi$ by pre-calibrating the first moments of the LPM. This ensures faster and more systematic convergence to the global minimum of $\chi$.

To evaluate the goodness of fit, we use the maximum of the relative residuals over the $\mathrm{N}$ reference tracer concentrations $\rho$ :

$$
\rho=\max _{n \in \llbracket 1 ; \mathrm{N} \rrbracket} \frac{\left|\nu_{n}\right|}{C_{\operatorname{Tr}_{n}}^{\mathrm{ref}}} .
$$

$\rho$, expressed in $\%$, gives the relative error made on the tracer concen235 
experimental uncertainties on field measurements are of the same order of magnitude (Cook \& Solomon, 1997). We choose to express the residual with the maximum of the residuals obtained to calibrate one tracer so that the values taken by $\rho$ do not depend on the number of parameters of the LPM. The maximum defining $\rho$ highlights more the possible deviations of the model than the quadratic norm of the errors.

\subsection{Predictive performances of LPMs}

We derive the quartiles of the calibrated LPMs. As for the reference TTD, the quartiles of the LPMs $Q_{1}^{\left(\pi_{1}, \cdots, \pi_{\mathrm{N}}\right)}, Q_{2}^{\left(\pi_{1}, \cdots, \pi_{\mathrm{N}}\right)}$ and $Q_{3}^{\left(\pi_{1}, \cdots, \pi_{\mathrm{N}}\right)}$ correspond to the prediction of the renewal time at which $25 \%$ (resp. $50 \%$ and $75 \%$ ) of the water in the aquifer is renewed. To evaluate the predictive performance of the LPMs we compare the reference renewal times given by TTDs to the prediction given by LPMs. We introduce the comparison criterion $\theta$ (given in years) :

$$
\theta=\frac{1}{3} \sum_{i=1}^{3}\left|Q_{i}^{\mathrm{ref}}-Q_{i}^{\left(\pi_{1}, \cdots, \pi_{\mathrm{N}}\right)}\right|
$$

$\theta$ assesses the quality of the predictions given by a LPM on the quartiles. Small $\theta$ values indicate a good agreement. The analysis of the performance criterion $\theta$ will be made over all the aquifer with the different LPMs model.

This methodology is generic and can be applied to any aquifer model on which transport simulations can be performed. The most important limitation comes from the characteristic time ranges of the available atmospheric tracers. In the following, the analysis is relevant for recent circulations (less

than 60 years in practice). Extension to longer times with different sets of tracers is discussed in section 5 . 


\section{The 3D numerical model of Plœemeur pumping site}

The site of Plomeur has several advantages for this study. It is a 3D crystalline aquifer with circulations of the order of some tens of years. Although developing in complex fractured geological structures, the flow pattern is fully $3 \mathrm{D}$ but remains mostly convergent to the actual pumping site. Moreover, it has been studied for almost 20 years and calibrated flow models have been developed (Carn, 1990; Le Borgne et al., 2006; Touchard, 1999).

\subsection{Description of the 3D crystalline aquifer model}

This study is based on one of the models of the Plœemeur aquifer developed by Leray et al. (2012). The Ploemeur aquifer is located in the south of Brittany (France) within a crystalline basement. It is produced from a single well since 1991 at $110 \mathrm{~m}^{3} / \mathrm{h}$ for the drinking water supply of the nearby city.

The site is composed of four major structures (Figure 3). Two granitic plutons outcrop North and South of the site acting as no-flow boundaries. The recharge of $200 \mathrm{~mm} /$ year in average leaks into semi impervious overlying micaschists. A gently dipping fractured zone further drains recharge to the pumping well. This transmissive structure at the contact between the southern granite and the micaschists, named the contact zone, constitutes the 270 aquifer. Another transmissive structure, a subvertical fault oriented North $20^{\circ}$, while clearly marked on the geological map, only slightly impacts the flow pattern (Leray et al., 2012). The pumping well is located at the intersection between the subhorizontal contact zone and the subvertical North $20^{\circ}$ fault. Table 2 sums up the properties of the hydrogeological model used. The flow and transport model used in this study refers to the "deep" model 
of Leray et al. (2012). It has been calibrated with data at the pumping well of the mean piezometric level (-5.5 m above sea level) and of the CFC-12 atmospheric concentration measured in 2009 (30 years) (Leray et al., 2012). Transport simulations are performed by forward-tracking particles along the steady-state velocity field (advective transport only), mixing occurring by convergence of the flow lines within the sampling zones. Numerical methods were performed using the H2OLAB platform (Erhel et al., 2009) and are thoroughly described in (Leray et al., 2012).

\subsection{In-silico reference results for the Plømeur aquifer}

\subsubsection{Derivation reference TTDs per the in-silico model}

Following the methodology of section 2.1, reference TTDs are obtained using the previously described hydrogeological model. Sampling zones have been designed in such a way as to stay close to field measurements conditions (Figure 4). They are parallelepiped that cross the contact zone over all its thickness to sample the aquifer. 73 sampling zones of characteristic width of 250 meters map the full extent of the aquifer contributing to the pumping zone. TTDs are built on all the flow lines crossing the sampling zones and are located at the center of the box. The issued TTDs fundamentally represent the residence time of the solutes flowing through the sampling zones around their center analogously with field sampling where abstracted water comes from a limited zone around the piezometer or well. Their size and number have been set in order to meet computational capacities with enough flow lines crossing the sampling zones and not too many sampling zones for fitting the seven LPMs.

TTDs display a wide variety of shapes (Figure 5) closer to the exponential 
distribution at the well $(\mathrm{dW}=0)$ and more Inverse Gaussian like at intermediary distance $(\mathrm{dW}=600 \mathrm{~m})$ or shifted exponential further away $(\mathrm{dW}=1700$ $\mathrm{m})$. Whatever the sampling zone, we have checked that TTDs converged to a steady shape with the number of particles used. In practice, at least 400 particles should intersect the sampling zone to reach convergence. This target is attained with an overall injection of $10^{6}$ flow-weighted particles on the free surface. Most of the time, the number of particles crossing the sampling zones is well above the 400 particle threshold, and of the order of $10^{4}$ to $10^{5}$.

\subsubsection{Derivation of the apparent ages per the in-silico model}

Reference tracer concentrations are computed for CFC-11, $\mathrm{SF}_{6}$ and ${ }^{85} \mathrm{Kr}$ in all the sampling zones at year 2010. Maps of the different apparent ages are built by interpolating these 73 reference tracer concentration values (Figure 6). Following the differences in the slopes of $\mathscr{C}_{\operatorname{Tr}}$, we recover that $\hat{A}_{\mathrm{Kr}}<\hat{A}_{\mathrm{SF}_{6}}<\hat{A}_{\mathrm{CFC}}$ as already indicated by (Waugh et al., 2003). For the ${ }^{85} \mathrm{Kr}$ however, we had to consider the slope of the input tracer concentration corrected from its radioactive decay: $\mathscr{C}_{\operatorname{Tr}} e^{-\lambda}$. In this case, the slope of the corrected atmospheric tracer concentrations

$$
\frac{\mathrm{d}}{\mathrm{d} t} \mathscr{C}_{\mathrm{CFC}}<\frac{\mathrm{d}}{\mathrm{d} t} \mathscr{C}_{\mathrm{SF}_{6}}<\frac{\mathrm{d}}{\mathrm{d} t} \mathscr{C}_{\mathrm{Kr}} e^{-\lambda}
$$

match the inverse of the order of the different ages.

\subsubsection{Derivation of actual renewal times per the in-silico model}

Finally, maps of the different renewal times (so that 25, 50 and $75 \%$ of the water is renewed) across the whole watershed are derived from the in-silico modeling (Figure 7). $Q_{1}, Q_{2}$ and $Q_{3}$ all display the same overall South-North 

spheric tracer data. The analysis is performed independently on the 73 TTDs obtained in the contact zone of the Plœmeur aquifer described in section 3 with the 7 LPMs models of section 2.2. Depending on the LPM shape, on the number of parameters, we determine the goodness of fit $\rho$ in percentage (equation 7) and the prediction accuracy $\theta$ in years (equation 8). We present systematically the mean and standard deviations of $\rho$ and $\theta$ over the 73 sampling zones denoted as $\bar{\rho}, \bar{\theta}, \sigma(\rho), \sigma(\theta)$, as well as the percentage of the zones for which the discrepancy of the observed versus modeled groundwater ages 
exceeds $10 \%(P(\rho>10 \%))$ (table 3$)$.

\subsection{1-parameter LPMs calibrated on CFC-11}

Statistics on $\rho$ and $\theta$ are summarized in the upper part of table 3. The residual for the Dirac distribution $\rho$ is always equal to 0 . This is expected because by centering the Dirac on the apparent age given by the CFC-11, the residual is equal to $0 \mathrm{i}$. e. the Dirac distribution perfectly fits the CFC-11 tracer observable. At the opposite, for the exponential distribution, the mean and standard deviation of the residual $(\bar{\rho}$ and $\sigma(\rho))$ are very high. They are above the $10 \%$ acceptable limit for $45 \%$ of the sampling zones. The spatial distribution of $\rho$ (Figure 8) shows that $\rho$ is high away from the discharge zone but always under $10 \%$ close to the convergence zone of the aquifer where a broad range of transit times are collected. The limits of the exponential distribution come from the large weight given to the more recent atmospheric tracer concentrations, which represent the largest values (Figure 1). Considering that the CFC-11 atmospheric concentration is essentially increasing over the last 75 years, the minimum concentration that can be obtained with any exponential model is the one obtained when the exponential model tends to a uniform distribution over the last 75 years. This minimum concentration is thus equal to the mean atmospheric concentration of $\mathrm{CFC}-11$ over the same period corresponding to an age given by equation 2 of about 40 years. Away from the discharge zone, apparent ages in the watershed larger than 40 years cannot be fitted by the exponential distribution. The same type of inadequacy occurs for all other atmospheric tracers like ${ }^{85} \mathrm{Kr}$ or $\mathrm{SF}_{6}$.

Predictions of the renewal time of $25 \%$ of the groundwater to the sampling zones $\left(Q_{1}\right)$ show that neither the exponential nor the Dirac distribution 
model (Figure 9) can give everywhere accurate predictions of the reference re-

newal times displayed by Figure 7a. For the Dirac distribution, the quartiles $Q_{1}, Q_{2}$ and $Q_{3}$ are taken as the characteristic time of the Dirac distribution. The Dirac is predictive only very close to the diverging recharge areas while the exponential model is accurate only in the discharge converging areas. Conversely the Dirac LPM overestimates the renewal times while the exponential LPM underestimates them in most of the aquifer. None of the model can give even close predictions away from the pumping and recharge zones. Results for the $Q_{2}$ and $Q_{3}$ are very similar and are thus not displayed.

While highly attractive because characterized by only one parameter, the Dirac and exponential models are relevant only in very limited zones of the aquifer. For the Dirac distribution, these zones are very far away from the pumping zone. For the exponential model, the relevant zones are only those very close to the pumping well. In between these two cases, other LPMs should be applied with more than one parameter.

\subsection{2-parameter LPMs calibrated on CFC-11 and ${ }^{85} \mathrm{Kr}$}

Fitting the 2-parameter models to $\mathrm{CFC}-11$ and ${ }^{85} \mathrm{Kr}$ concentrations gives both much better fits and predictions (middle part of Table 3). For both models, the fit of the concentrations is excellent with only 3 to 4 zones out of the 73 sampling zones for which $\rho$ is larger than $10 \%$. It means that both models are good for fitting concentrations almost everywhere in the aquifer.

Statistics on the prediction accuracy $\theta$ gives surprisingly very similar results for the Inverse Gaussian, Shifted Exponential and Uniform models despite the broadly differing shapes of the distributions (Figure 2). Average prediction accuracy $\bar{\theta}$ is of 3.5 years for groundwater ages of the order of 
decades (Table 3). Standard deviations of the accuracy $\sigma(\theta)$ are small and less than 2 years. Models do not perform well in only some restricted areas in the north of the aquifer far away from the pumping well where velocities are substantially smaller and travel times larger (Figure 10). Outside of these areas, predictions are two to three times more accurate than for the 1-parameter Exponential and Dirac models and lead to only small errors in absolute values. A few years of differences can be deemed acceptable compared to the broad time ranges of the TTD, which can be evaluated at 37 years by the span of the uniform distribution $\left[t_{0} ; t_{1}\right]$. So the accuracy in terms of predictions is of the order of a few years on some decades.

The agreement with the reference tracer concentrations measured by $\rho$ displays relatively more differences between the Inverse Gaussian, Shifted Exponential and Uniform models. The inverse Gaussian gives on average much better agreements than the two other distributions. The uniform model leads to larger deviations than the 2 other models. $12 \%$ of the zones have more than $10 \%$ deviations to the reference concentrations $(P(\rho>10 \%)$ in Table 3). Maximum deviation is about 38\%, more than twice larger than for the 2 other models. This is consistent with the characteristic shape of the TTDs that looks more inverse Gaussian than uniform, and in a less extent than the shifted exponential (Figure 5). While the inverse Gaussian model is more representative of the TTD, it does not yield higher predictive capability, 410 as if predictions depend more on some basic characteristics of the distribution like its two first moments than on its precise shape. It is confirmed by the spatial distribution of the $25 \%$ renewal times (Figure 10). All three LPMs lead to very similar patterns. There are only somewhat steeper gradients for 
the exponential shape likely coming from the initial irregularity of its shape. Parameter Model should have a shape related to the real shape of the TTD. As shown with the comparison of the 2-parameter models, the LPM does not 
have to follow all the variations of the TTD. It should not be however completely off as shown here. The shape of the distribution taken as the prior in the Bayesian framework remains a key factor of the prediction accuracy and should be carefully chosen depending on the hypothesized flow pattern likely to happen.

\section{Discussion}

The previous results show that the quality of the calibration does not grant the accuracy of the predictions. The lowest $\rho$ values are obtained for the Dirac distribution (residual always equal to 0 ) and for the sum of two Dirac distributions. However, they give the worst predictions of renewal times. It is not a matter of the number of parameters as the sum of two Dirac has three parameters. It is rather the lack of relevance of the Dirac distribution away from the recharge zones, where it is in fact expected to be relevant. In the discharge zone, it still perfectly fits the observed CFC-11 concentration but it is no longer relevant. More generally, the concentration residual $\rho$ obtained with the seven candidate LPMs cannot be linked to the accuracy of the predictions. While $\rho$ is interesting because it is the sole quantitative criterion that can be obtained in the field, it is neither a necessary nor a sufficient condition for the accuracy of the predictions.

We use the quartiles of the renewal time distribution to assess the quality of the predictions rather than the full distribution. The quartiles correspond to the renewal time of $(25,50$ or $75 \%)$ of the water within the sampling zones. This choice is motivated by the two following reasons. First, quartiles give numerical indicators of practical interest while comparing shapes of LPMs 
as in Eberts et al. (2012) is more qualitative and remote. Quartiles can be straightforwardly used to build statistics on prediction errors as in table 3 . Quantitative indicators could still be derived from the comparison of the LPMs and TTDs shapes like the Root Mean Square Error (RMSE). However they can be artificially large because of the irregularities of the TTDs (see figure 2) that cannot be accurately reproduced by any reduced model (Green et al., 2014). Besides, these irregularities are of little influence to integrated 470 predictions like renewal times. The second motivation for using quartiles is indeed their integrative nature. Management decisions depend on global indicators like renewal times, flushing and dilution capacities rather than on detailed but approximate distribution shapes. Quartiles correspond to the time after which 25,50 or $75 \%$ of the water reaching a piezometer or well have been flushed. On top of the median (second quartile $Q_{2}$ ) Green et al. (2014), we also use the first and third quartiles to enhance sensitivity of the predictions to the variance and skewness of the TTDs.

It is not the concentration fit nor the number of parameters of the model but rather the likelihood of the distribution shape that conditions the accuracy of the predictions (table 3) as also concluded by Green et al. (2014). Thus "likely" distributions imply considering analytic distributions with at least two parameters. Indeed, LPMs with only one parameter (Dirac, exponential) give accurate predictions only in very narrow sections of the aquifer. 2-parameter LPMs on the contrary give already very accurate predictions that cannot be made much better using an additional third parameter. The 2-parameter LPMs capture in various ways the mean and standard deviation of the distribution, predictions becoming almost insensitive to higher order 
moments. Because they are flexible and can evolve continuously from Dirac to broad distributions, the 2-parameter LPMs are appropriate almost everywhere in the aquifer as shown by the similarity of Figures $7 \mathrm{c}$ and $12 \mathrm{~b}$. There are only some spurious variations of $Q_{3}$ that are corrected by the 3-parameter shifted inverse Gaussian model. In fact the residence time distributions display some initial shift outside of the pumping area linked to the transit time of the water through the micaschist aquitard zone to get to the aquifer sampling zones (Figure 5). But even this striking distribution feature is not essential for establishing good predictions.

The distribution of $Q_{1}$ prediction errors represented on Figure 13 for the tested distributions confirm these conclusions. 1-parameter LPM errors are much larger than those of the 2 and 3-parameter LPMs. Errors are considerably reduced from 1-parameter LPMs to 2-parameter LPMs. 3-parameter LPMs do not significantly improve the predictions. When the shape of the LPM deviates more from the reference TTD, errors become somewhat larger like for the Dirac composition and uniform distributions. The error distribution of Figure 13 additionally reveals that 1-parameter LPMs prediction errors are not symmetric (centered on 0). The Dirac LPM tends to underestimate renewal times while the exponential LPM tends to overestimate them. This comes from the specific shape of these LPMs. The exponential distribution overestimates the large transfer times to fit the right mean. On the opposite, the Dirac distribution underestimates the variability, underes-

510 timates $Q_{1}$ predictions and overestimates $Q_{3}$ predictions. In comparison to that, prediction errors of 2-parameter LPMs and of the 3-parameter shifted inverse Gaussian appear to have error in predictions centered on 0, which 
means that in average, predictions are not biased by a tendency to over- or under-estimate renewal times.

Appropriate distributions should be continuous and relatively broad covering a wide range of transit times. Beyond these general characteristics, the details of the distributions have little importance. The Inverse Gaussian and the Shifted Exponential distributions give the same prediction quality. We can show that it is a general result. We consider an Inverse Gaussian distribution with parameters $T$ and $P e$ respectively equal to 20 and $3 / 2$. From equation 1 we compute the tracer concentrations and ages obtained with such a TTD and find $\hat{A}_{\mathrm{CFC}}^{\mathrm{IG}}=1986$ and $\hat{A}_{\mathrm{Kr}}^{\mathrm{IG}}=1997$. With the method developed in section 2.2.2, we determine the parameters $T$ and $t_{0}$ of the shifted exponential distribution that fits best these concentrations (equation 5). The residual $\rho$ is equal to 3\%. The two distributions (Figure 14) are very close and their cumulative density function lead to extremely close predictions. Similar conclusions have been drawn by Waugh et al. (2003) with an inverse Gaussian and a combination of two inverse Gaussian distributions.

As the number of parameters has been taken equal to the number of available concentrations, the practical consequence of the previous results is to seek for two tracers in the same age range to reach satisfying predictions. Indeed, one tracer concentration is not enough to determine two parameters. Two tracer concentrations are necessary to give the complementary information needed to inform the mean and standard deviation of the TTD 535 in this given age range, consistent with the theoretical result of Massoudieh \& Ginn (2011). Redundant tracers remain of key interest for checking potential contamination, excess air and geogenic production, and for reducing 
the uncertainties inherently linked to measurement errors (Green et al., 2014; Massoudieh et al., 2012). To ensure complementarity, the atmospheric tracer article can be applied to a broad variety of aquifer models. We may expect different outcomes when mixing different characteristic transit times on a broader range (e.g. [0;1000] years) either from different aquifers or from an aquitard and an aquifer. In such cases the combination of Dirac distributions might be more appropriate. Two tracers on different age ranges (for example CFC-11 and ${ }^{39} \mathrm{Ar}$ ) might be tested to characterize different parts of the TTD. This is a valuable method to identify potential mixing of younger and older 
waters in the aquifer but cannot be apply directly to determine the shape of the TTD. Indeed, the younger tracer characterizes the local flow (with transit times under 100 years) whereas the older tracer characterizes more regional flow with longer transit times. Other multitracer approaches could also be tested by considering the ratio of the same date ranging tracer concentrations. Indeed, such ratios have the advantage to be independent of the mixing affecting the groundwater. With two ratios, in the same way as what have been done previously, one can characterize the piecewise TTD on the support of the date ranging of these tracers. Building two ratios however requires to provide at least three independent tracer concentrations and not two. Moreover, the choice of predictive indicators gains in importance as soon as the TTD gets broader (i. e. with an increasing coefficient of variation, ratio of standard deviation upon average). In this case, more precise metrics (deciles or even centiles) instead of quartiles might be considered to get indicators with useful predictive power.

\section{Conclusion}

We develop a methodology to assess Lumped Parameter Model prediction 580 capacities in realistic 3D aquifer cases. Lumped Parameter Models (LPMs) are simple analytical distributions designed to approximate natural transit time distributions (TTDs). LPMs are appealing for establishing predictions directly from groundwater age data. Predictions are generally framed in some kind of aquifer renewal times and do not require involved hydrogeological models. Our methodology assesses the prediction capacities of LPMs on realistic $3 \mathrm{D}$ aquifer synthetic models. Aquifer modeling cannot be avoided 
as reference TTDs as well as reference renewal time predictions cannot be directly measured on the field. Beyond LPMs assessment, we aim at finding the right balance between the information available in groundwater age data and the knowledge required to establish accurate predictions. We simply rate the amount of available information as the number of parameters that can be calibrated on a set of groundwater age data. When considering gas molecules like $\mathrm{CFCs}, \mathrm{SF}_{6}$ and ${ }^{85} \mathrm{Kr}$ with sufficiently different atmospheric concentration chronicles, the amount of available information is the number of parameter of the LPM chosen equal to the number of tracers.

We apply this methodology on the kilometric-scale crystalline aquifer of Plœmeur (France). The aquifer is located in a sloping contact zone between granites and micaschists overlain by a semi-pervious aquitard. Flow pattern is globally convergent to a well steadily produced for the nearby city. A previous model calibrated on head and age data shows that local topographical as well as geological features yield to complex 3D flow structures. It results in a variety of Transit Time Distributions ranging from Dirac-like close to recharge zones to exponential-like at the well. Outside of these zones, distributions cannot be evidently modeled as one of the classically used LPM like the composition of Diracs, the shifted exponential or the inverse Gaussian distributions. Extensive analysis on 73 sampling zones located everywhere in the aquifer however shows that LPMs can be highly effective for establishing accurate predictions. The 2-parameter inverse Gaussian or shifted exponential LPMs calibrated on CFC-11 and ${ }^{85} \mathrm{Kr}$ concentrations both yield almost ev610 erywhere accurate renewal times at less than $10 \%$ precision. By comparison, the 1-parameter exponential and Dirac LPMs calibrated on CFC-11 could 
not give any relevant predictions in most of the aquifer. The 3-parameter models calibrated with the additional knowledge of SF6 do not lead to any better prediction.

For the type of studied crystalline aquifer system, we conclude that two tracers with sufficiently different atmospheric concentration chronicles give highly accurate renewal time predictions, provided that hydrogeologically relevant LPMs be used. Relevant LPM shapes are also necessary to yield to unbiased estimations. In this case, the relevant LPMs should be broad and relatively smooth like the shifted exponential or inverse Gaussian distributions. More details on the distribution provided by additional tracers are not necessary for the type of renewal time predictions targeted. On the contrary, distributions made up of some Dirac combinations do not give any close predictions despite good agreements with the reference tracer concentrations. More extensive analysis should be undertaken in a wider variety of realistic aquifer cases to assess the representativeness and relevance of these conclusions.

\section{References}

\section{References}

${ }_{630}$ Basu, N. B., Jindal, P., Schilling, K. E., Wolter, C. F., \& Takle, E. S. (2012). Evaluation of analytical and numerical approaches for the estimation of groundwater travel time distribution. Journal of Hydrology, 475, 65-73. doi: $\{10.1016 / j \cdot j$ hydrol . 2012.08.052\}.

Bear, J. (1973). Dynamics of Fluids in Porous Media. Dover Publications. 
Castro, M., \& Goblet, P. (2005). Calculation of ground water ages A comparative analysis. Ground Water, 43, 368-380. doi:\{10.1111/j. $1745-6584.2005 .0046 . x\}$.

Cook, P., \& Bohlke, J. (1999). Determining timescales for groundwater flow 
and solute transport. In Environmental Tracers in Subsurface Hydrology (pp. 1-30). Kluwer Acad., Norwell, Mass.

Cook, P., \& Herczeg, A. (2000). Environmental tracers in subsurface hydrology. United States: Kluwer Academic Publishers.

Cook, P., Love, A., Robinson, N., \& Simmons, C. (2005). Groundwater ages in fractured rock aquifers. Journal of Hydrology, 308, 284-301. doi:\{10. 1016/j.jhydrol.2004.11.005\}.

Cook, P., \& Solomon, D. (1997). Recent advances in dating young groundwater: Chlorofluorocarbons, H-3/He-3 and Kr-85. Journal of Hydrology, 191, 245-265. doi: $\{10.1016 / \mathrm{S} 0022-1694$ (96)03051-X\}.

Corcho Alvarado, J. A., Purtschert, R., Barbecot, F., Chabault, C., Rueedi, J., Schneider, V., Aeschbach-Hertig, W., Kipfer, R., \& Loosli, H. H. (2007). Constraining the age distribution of highly mixed groundwater using 39 Ar: A multiple environmental tracer (H-3/He-3, Kr-85, Ar-39, and C-14) study in the semiconfined Fontainebleau Sands Aquifer (France). Water Resources Research, 43. doi:\{10.1029/2006WR005096\}.

Cvetkovic, V. (2012). A general memory function for modeling mass transfer in groundwater transport. Water Resources Research, 48. doi:\{10.1029/ 2011WR011657\}.

Dagan, G., Cvetkovic, V., \& Shapiro, A. (1992). A solute flux approach to transport in heterogeneous formations .1. the general framework. Water Resources Research, 28, 1369-1376. doi:\{10.1029/91WR03086\}. 
Delay, F., Ackerer, P., \& Danquigny, C. (2005). Simulating solute transport in porous or fractured formations using random walk particle tracking. Vadose Zone Journal, 4, 360-379.

Dentz, M. (2012). Concentration statistics for transport in heterogeneous media due to stochastic fluctuations of the center of mass velocity. Advances in Water Resources, 36, 11-22. doi:\{10.1016/j .advwatres. 2011.04.005\}.

Eberts, S. M., Boehlke, J. K., Kauffman, L. J., \& Jurgens, B. C. (2012). Comparison of particle-tracking and lumped-parameter age-distribution models for evaluating vulnerability of production wells to contamination. Hydrogeology Journal, 20, 263-282. doi:\{10.1007/s10040-011-0810-6\}.

Engdahl, N., \& Maxwell, R. (2014). Approximating groundwater age distributions using simple streamtube models and multiple tracers. Advances in Water Resources, 66, 19-31.

Erhel, J., de Dreuzy, J.-R., Beaudoin, A., Bresciani, E., \& Tromeur-Dervout, D. (2009). A parallel scientific software for heterogeneous hydrogeoloy. In Parallel Computational Fluid Dynamics 2007 (pp. 39-48). Springer.

Eriksson, E. (1958). The possible use of tritium for estimating groundwater storage. Tellus, 10, 472-478.

Etcheverry, D., \& Perrochet, P. (2000). Direct simulation of groundwater transit-time distributions using the reservoir theory. Hydrogeology Journal, 8, 200-208.

700 Ginn, T. R. (1999). On the distribution of multicomponent mixtures over 
generalized exposure time in subsurface flow and reactive transport: Foundations, and formulations for groundwater age, chemical heterogeneity, and biodegradation. Water Resources Research, 32, 1395-1407.

Ginn, T. R., Haeri, H., Massoudieh, A., \& Foglia, L. (2009). Notes on Groundwater Age in Forward and Inverse Modeling. Transport in Porous Media, 79, 117-134. doi:\{10.1007/s11242-009-9406-1\}.

Goderniaux, P., Davy, P., Bresciani, E., de Dreuzy, J.-R., \& Le Borgne, T. (2013). Partitioning a regional groundwater flow system into shallow local and deep regional flow compartments. Water Resources Research, 49, 2274-2286. doi:\{10.1002/wrcr. 20186\}.

Green, C., Zhang, Y., Jurgens, B., Starn, J., \& Landon, M. (2014). Accuracy of travel time distribution (ttd) models as affected by ttd complexity, observation errors, and model and tracer selection. Water Resources Research, 50, 6191-6213. URL: http://dx.doi.org/10.1002/ 2014WR015625, doi:10.1002/2014WR015625.

Haggerty, R., \& Gorelick, S. (1995). Multiple-rate mass-transfer for modeling diffusion and surface-reactions in media with pore-scale heterogeneity. Water Resources Research, 31, 2383-2400. doi:\{10.1029/95WR10583\}.

Haitjema, H. (1995). On the residence time distribution in idealized groundwatersheds. Journal of Hydrology, 172, 127-146. doi:\{10.1016/ 0022-1694(95) 02732-5\}.

Katz, B., Bohlke, J., \& Hornsby, H. (2001). Timescales for nitrate contam- 
ination of spring waters, northern Florida, USA. Chemical Geology, 179, 167-186. doi:\{10.1016/S0009-2541(01)00321-7\}.

Leray, S., de Dreuzy, J.-R., Bour, O., \& Bresciani, E. (2013). Numerical modeling of the productivity of vertical to shallowly dipping fractured zones in crystalline rocks. Journal of Hydrology, 481, 64-75. doi:\{10. 1016/j.jhydrol.2012.12.014\}.

Leray, S., de Dreuzy, J.-R., Bour, O., Labasque, T., \& Aquilina, L. (2012). 
Contribution of age data to the characterization of complex aquifers. Journal of Hydrology , 464, 54-68. doi:\{10.1016/j .jhydrol.2012.06.052\}.

Lerner, D., \& Papatolios, K. (1993). A simple analytical approach for predicting nitrate concentrations in pumped ground-water. Ground Water, 31, 370-375. doi:\{10.1111/j.1745-6584.1993.tb01837.x\}.

Long, A. J., \& Putnam, L. D. (2006). Translating CFC-based piston ages into probability density functions of ground-water age in karst. Journal of Hydrology, 330, 735-747. doi:\{10.1016/j . jhydrot.2006.05.004\}.

Luo, J., \& Kitanidis, P. (2004). Fluid residence times within a recirculation zone created by an extraction-injection well pair. JOURNAL OF HYDROLOGY, 295, 149-162. doi:\{10.1016/j.jhydrol.2004.03.006\}.

Maloszewski, P., \& Zuber, A. (1996). Lumped parameters models for interpretation of environmental tracer data. In Manual on Mathematical Models in Isotope Hydrology (pp. 9-58). IAEA, Vienna, Austria volume TECDOC-910.

Massoudieh, A., \& Ginn, T. (2011). The theoretical relation between unstable solutes and groundwater age. Water Resources Research, 47. doi:\{10. 1029/2010WR010039\}.

Massoudieh, A., Leray, S., \& de Dreuzy, J.-R. (2013). Assessment of the value of groundwater age time-series for characterizing complex steady-state flow systems using a bayesian approach. Applied Geochemistry, .

Massoudieh, A., Sharifi, S., \& Solomon, D. K. (2012). Bayesian evaluation of 
groundwater age distribution using radioactive tracers and anthropogenic chemicals. Water Resources Research, 48. doi:\{10.1029/2012WR011815\}.

McCallum, J., Cook, P., Simmons, C., \& Werner, A. (2014a). Bias of ap770 parent tracer ages in heterogeneous environments. Ground Water, 52, 239-250.

McCallum, J., Engdahl, N., Ginn, T., \& Cook, P. (2014b). Nonparametric estimation of groundwater residence time distributions: What can environmental tracer data tell us about groundwater residence time? Water Resources Research, 50, 2022-2038.

McGuire, K. J., \& McDonnell, J. J. (2006). A review and evaluation of catchment transit time modeling. Journal of Hydrology, 330, 543-563. doi: $\{10.1016 / j \cdot j$ hydrol .2006.04.020\}.

Neupauer, R., \& Wilson, J. (2002). Backward probabilistic model of groundwater contamination in non-uniform and transient flow. Advances in Water Resources, 25, 733-746. doi:\{10.1016/S0309-1708(02)00073-8\}.

Newman, B. D., Osenbrueck, K., Aeschbach-Hertig, W., Solomon, D. K., Cook, P., Rozanski, K., \& Kipfer, R. (2010). Dating of 'young' groundwaters using environmental tracers: advantages, applications, and research needs. Isotopes in Environmental and Health Studies, 46, 259-278. doi: $\{10.1080 / 10256016.2010 .514339\}$.

Ozyurt, N., \& Bayari, C. (2003). LUMPED: a Visual Basic code of lumped-parameter models for mean residence time analyses of ground- 
water systems. Computers \& Geosciences, 29, 79-90. doi:\{10.1016/

Rinaldo, A., Beven, K. J., Bertuzzo, E., Nicotina, L., Davies, J., Fiori, A., Russo, D., \& Botter, G. (2011). Catchment travel time distributions and water flow in soils. Water Resources Research, 47. doi:\{10.1029/ 2011WR010478\}.

810

Ruelleu, S., Moreau, F., Bour, O., Gapais, D., \& Martelet, G. (2010). Impact of gently dipping discontinuities on basement aquifer recharge: An example 
from Ploemeur (Brittany, France). Journal of Applied Geophysics, 70, 161-168. doi:\{10.1016/j.jappgeo.2009.12.007\}.

Sebilo, M., Mayer, B., Nicolardot, B., Pinay, G., \& Mariotti, A. (2013).

Long-term fate of nitrate fertilizer in agricultural soils. Proceedings of the National Academy of Sciences of the United States of America, 110, 18185-18189. doi:\{10.1073/pnas. 1305372110\}.

Simmons, C. (1982). A stochastic-convective transport representation of dispersion in one-dimensional porous-media systems. Water Resources Research, 18, 1193-1214. doi:\{10.1029/WR018i004p01193\}.

Tompson, A. F. B., \& Gelhar, L. W. (1990). Numerical simulation of solute transport in three-dimensional, randomly heterogeneous porous media. Water Resources Research, 26, 2541-2562. URL: http://dx.doi. org/10.1029/WR026i010p02541. doi:10.1029/WR026i010p02541.

Touchard, F. (1999). Caractérisation hydrogéologique d'un aquifère en socle fracturé: Site de Plomeur (Morbihan). Ph.D. thesis University of Rennes 1, France.

Varni, M., \& Carrera, J. (1998). Simulation of groundwater age distributions. Water Resources Research, 34, 3271-3281. doi:\{10.1029/98WR02536\}.

${ }_{830}$ Waugh, D., Hall, T., \& Haine, T. (2003). Relationships among tracer ages. Journal of Geophysical Research-Oceans, 108. doi:\{10.1029/ 2002JC001325\}.

Weissmann, G., Zhang, Y., LaBolle, E., \& Fogg, G. (2002). Dispersion of 
groundwater age in an alluvial aquifer system. Water Resources Research,

Zinn, B. A., \& Konikow, L. F. (2007). Potential effects of regional pumpage on groundwater age distribution. Water Resources Research, 43. doi:\{10. 1029/2006WR004865\}.

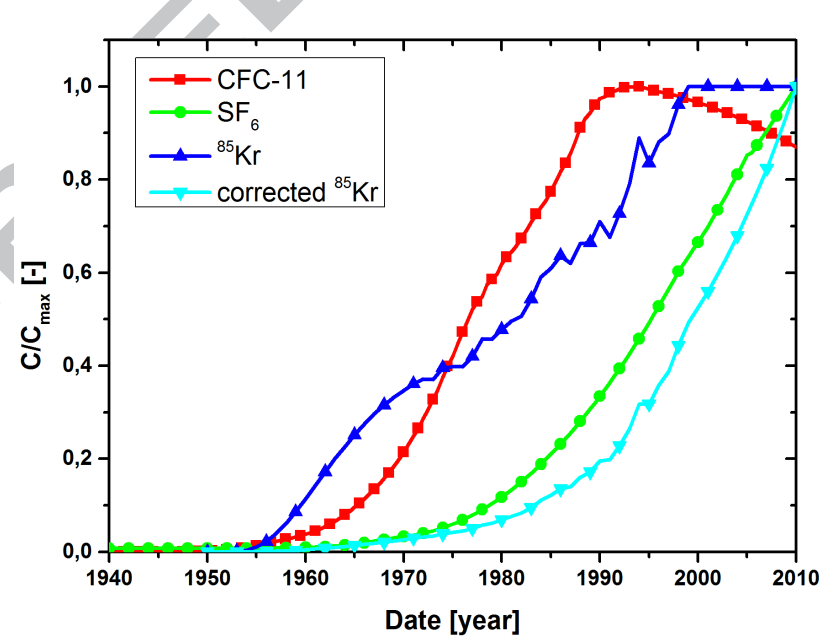

Figure 1: Atmospheric concentrations of CFC-11, $\mathrm{SF}_{6}$ and ${ }^{85} \mathrm{Kr}$ from 1940 to 2010. Being a radioactive tracer, ${ }^{85} \mathrm{Kr}$ concentration is corrected by its radioactive decay. Concentrations are normalized by their maximum to compare their relative evolution. 


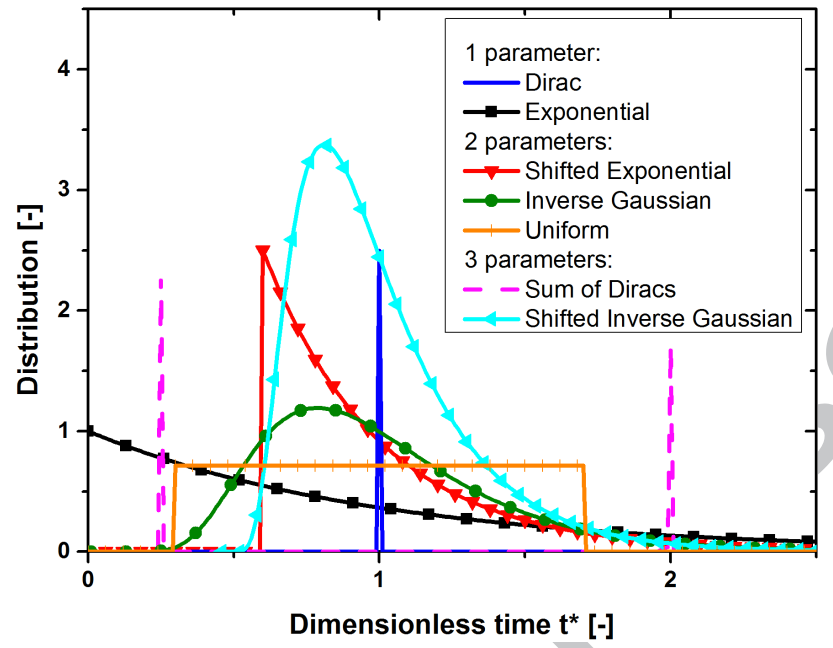

Figure 2: Comparison of the seven candidate LPM models as functions of the time $t$ normalized by the mean time $\mathrm{T}(\mathrm{t} / \mathrm{T})$. All distributions have the same mean and all distributions with more than one parameter have the same variance, but display quite different shapes.

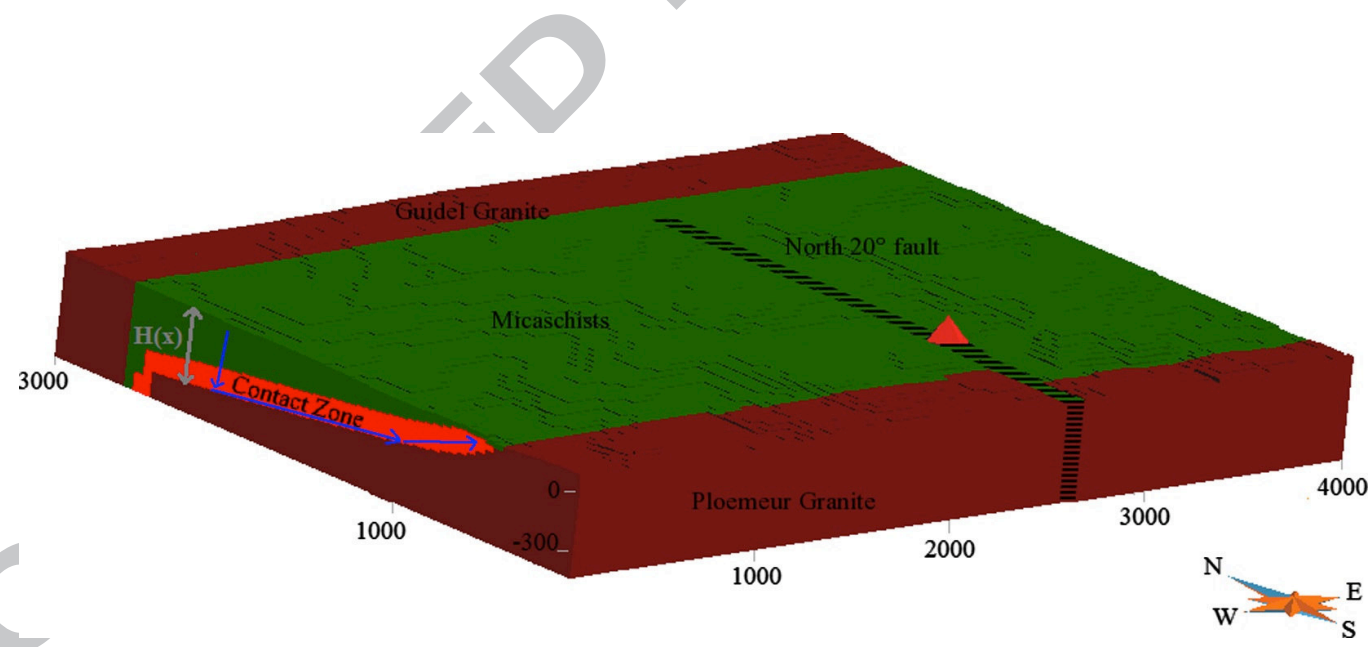

Figure 3: Conceptual hydrogeological scheme of the Plœmeur aquifer with the different geological units. Granites in the North and in the South are shown in brown. The micaschists (green) overly the contact zone (red) and all units are crosscut by the N20 fault (block dashed line). The pumping site is identified by the red triangle. Blue arrows sketch the characteristic flow direction. 


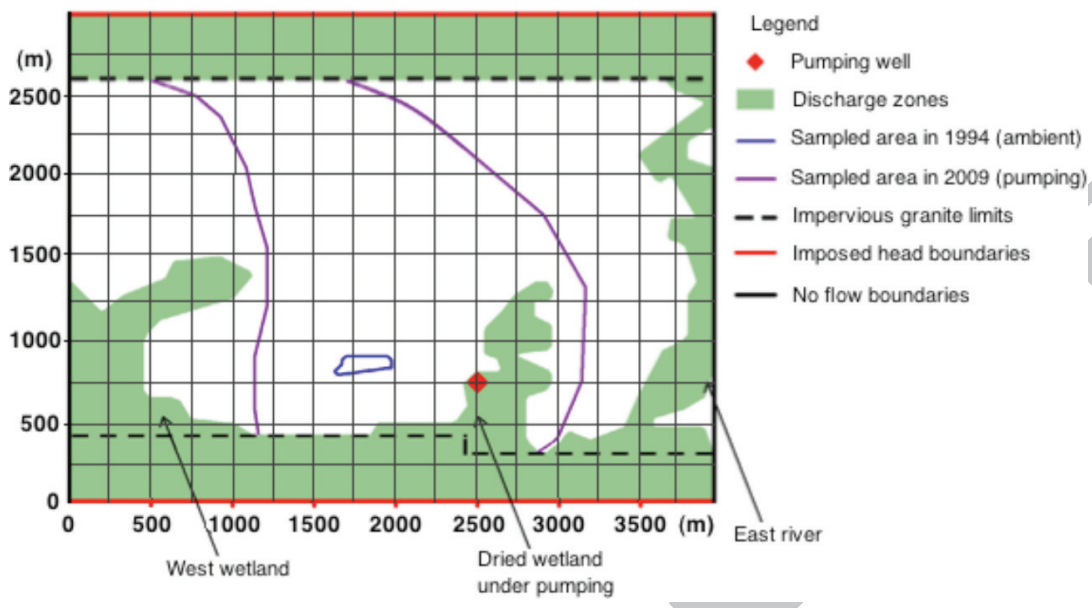

Figure 4: Map of numeric sampling strategy used to get observables and TTDs values overall the aquifer. Boxes are $250 \times 250 \mathrm{~m}$. Their heights are determined to span the contact zone.

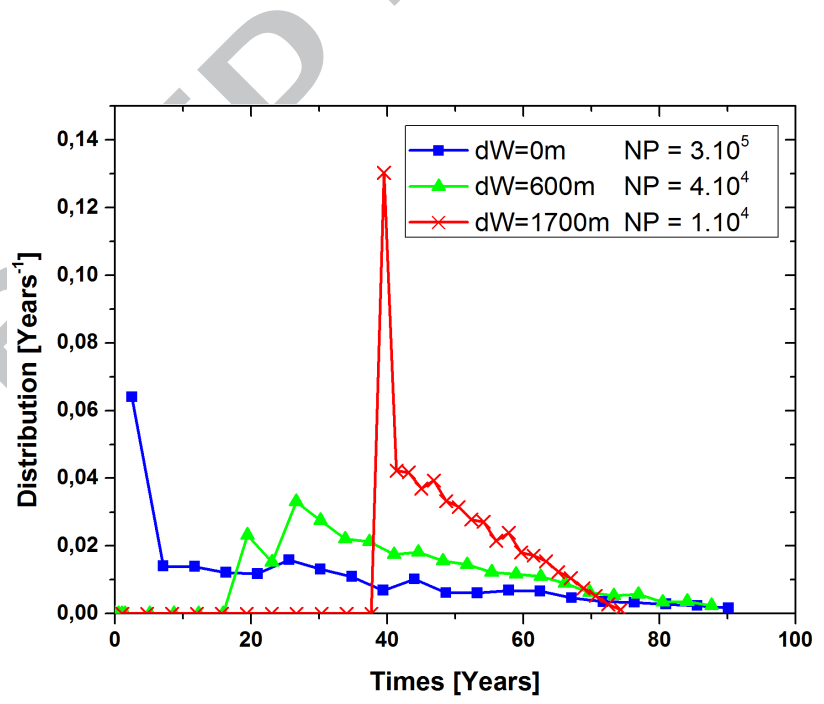

Figure 5: Transit time distributions obtained with the in-silico model of the Plœmeur site. $\mathrm{dW}$ is the distance between the sampling zone and the pumping well. NP is the number of particles intersecting the sampling zone used to build the transit times distributions. 

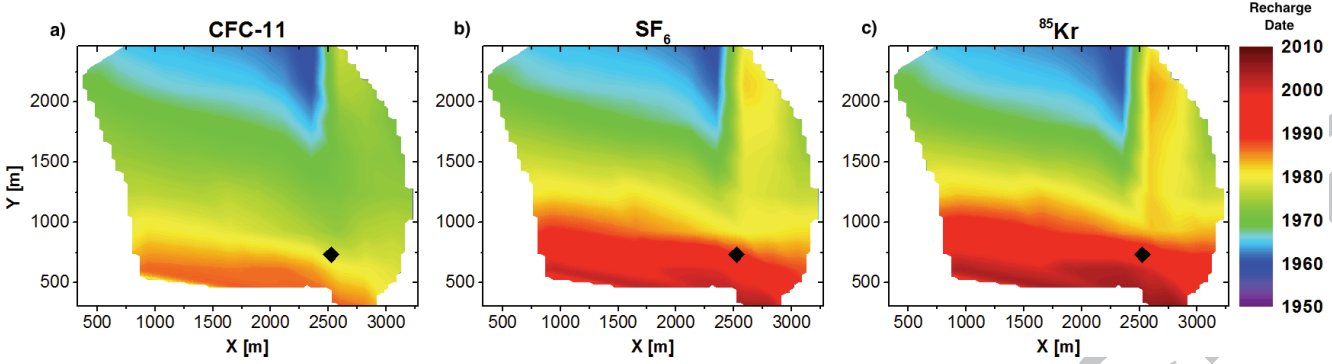

Figure 6: Map of the "apparent" recharge dates obtained with the in-silico model in the contact zone of the Plœmeur site. Contour of the map is determined by taking the supplying limit of the pumping well. From left to right: $\mathrm{CFC}-11, \mathrm{SF}_{6}$ and ${ }^{85} \mathrm{Kr}$ apparent ages. The pumping well is identified by the black square.
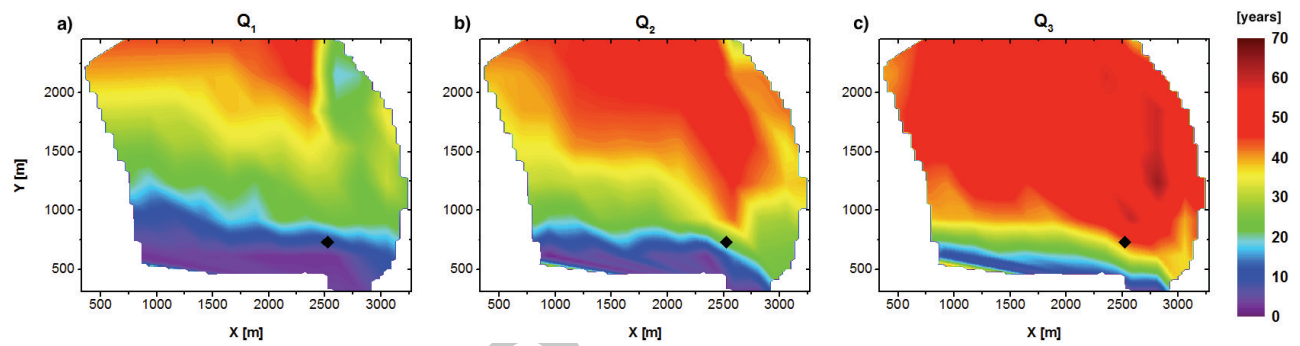

Figure 7: Map of the different renewal times (from left to right, times at which 25, 50 and $75 \%$ of the water is renewed) obtained with the in-silico model. The pumping well is identified by the black square.

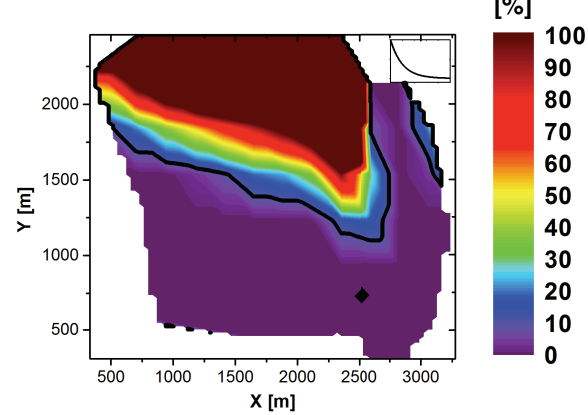

Figure 8: Map of the residual $\rho$ expressed in $\%$ obtained by fitting CFC-11 concentrations $C_{\mathrm{CFC}}^{\mathrm{ref}}$ with concentrations obtained from an exponential TTD. The black line identifies the limit for which the residual $\rho$ is equal to $10 \%$. The Exponential model gives acceptable residual only on the lower southern part of the aquifer close to the pumping site identifiable by the black square. 


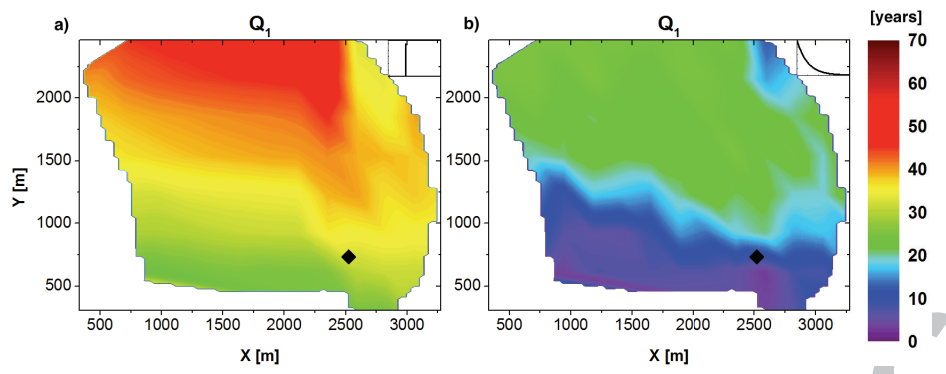

Figure 9: Characteristic renewal time of $25 \%$ of the water to the sampling zone $\left(Q_{1}\right)$ for the 1-parameter (a)Dirac LPM and (b) exponential LPM. The insert in the topright corner of the figure shows a sketch of the corresponding LPM.
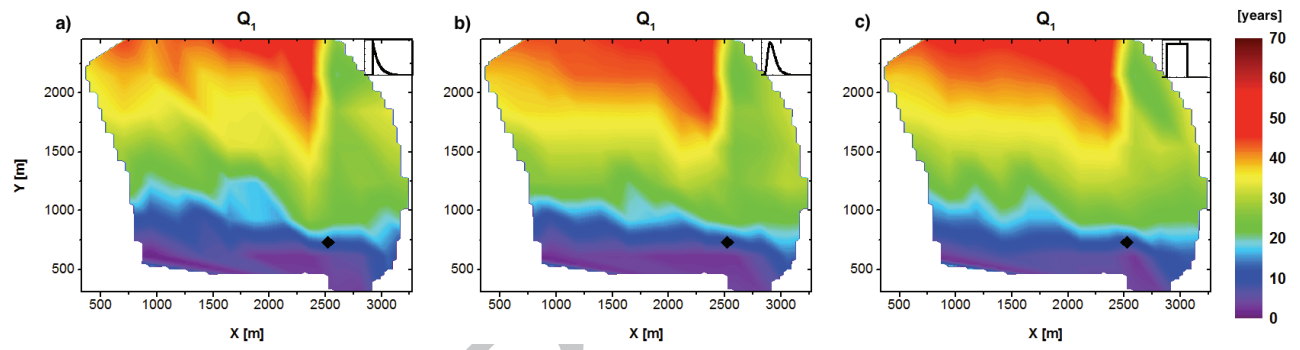

Figure 10: Characteristic renewal time of $25 \%$ of the water to the sampling zone $\left(Q_{1}\right)$ for the 2-parameter LPMs. From left to right, times derived by the shifted exponential model, by the inverse gaussian model and by the uniform model. The insert of each of the figure show on sketch of the LPM.
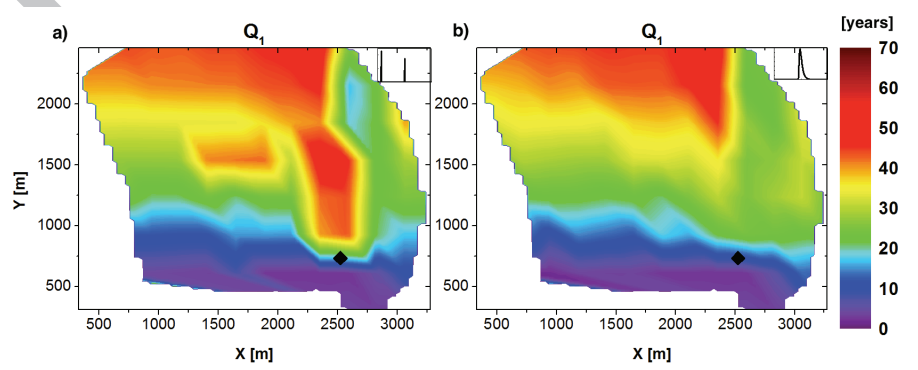

Figure 11: Characteristic renewal time of $25 \%$ of the water to the sampling zone $\left(Q_{1}\right)$ for the 3-parameter LPMs. From left to right, times derived by the sums of Dirac model and by the shifted inverse gaussian model. The insert of each of the figure show on sketch of the LPM. 

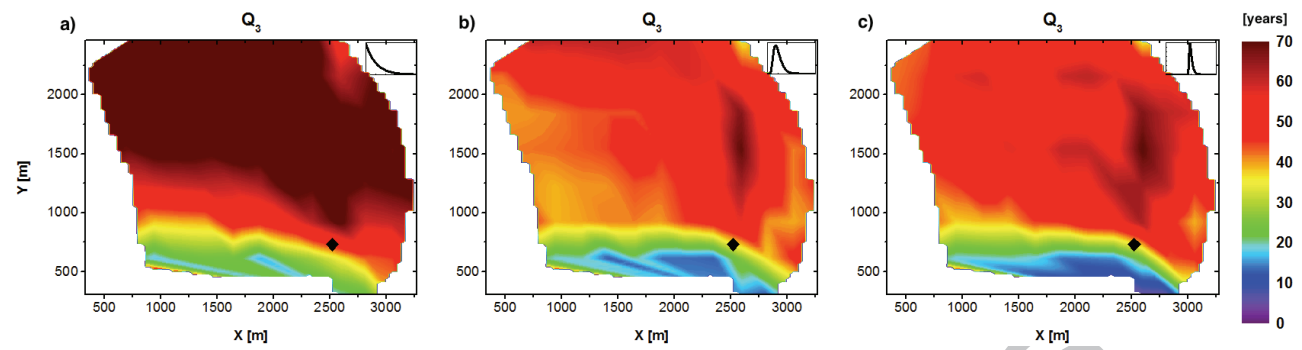

Figure 12: Characteristic renewal time of $75 \%$ of the water to the sampling zone $\left(Q_{3}\right)$. From left to right, times derived by a 1-parameter LPM (exponential model), by a 2parameter LPM (inverse gaussian) and by a 3-parameter LPM (shifted inverse gaussian). The insert of each of the figure show on sketch of the LPM.

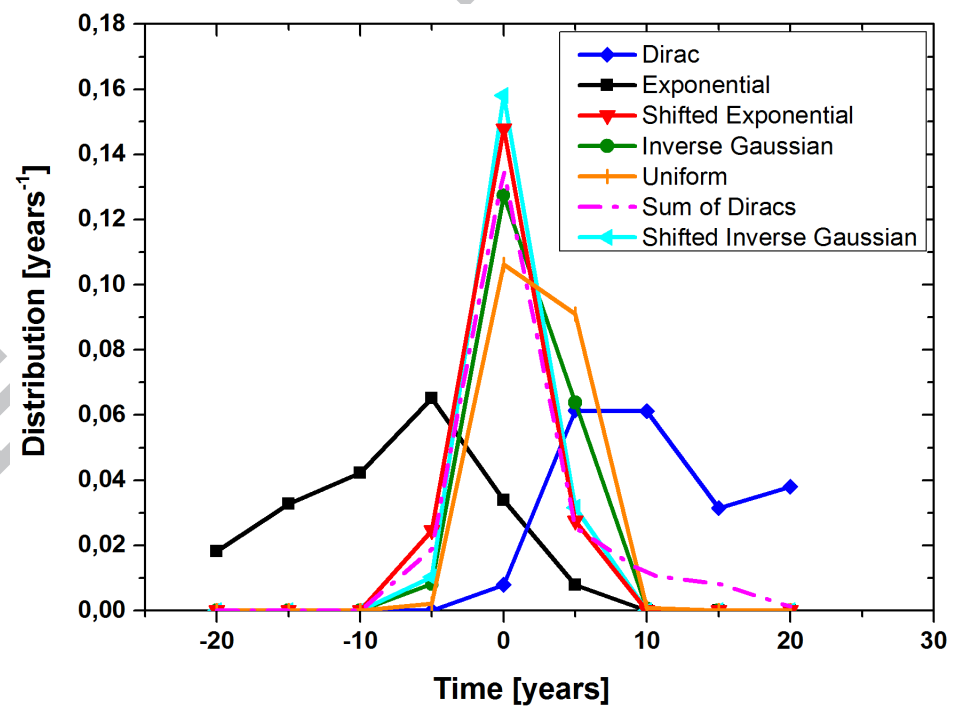

Figure 13: Histogram of the differences in predictions between reference $Q_{1}$ (25\% renewal time) and $Q_{1}$ predictions given by the LPMs. 

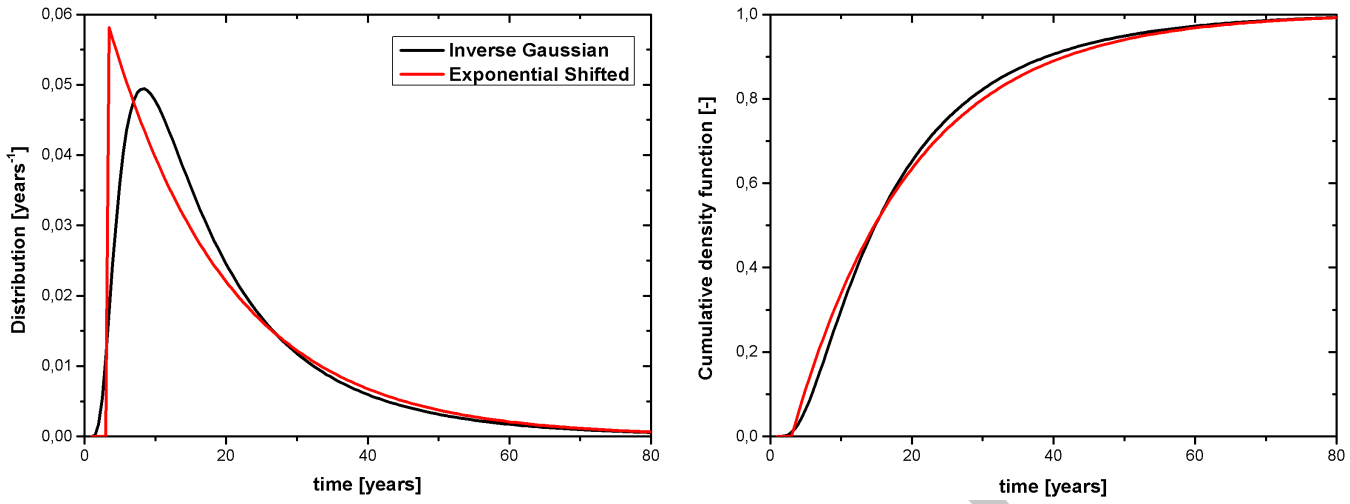

Figure 14: Distribution and cumulative density function associated of an Inverse Gaussian distribution with $(\mu, \lambda)=(20,30)$ years and of the Shifted Exponential distribution that fits the observables $C_{\mathrm{CFC}}^{\mathrm{IG}}$ and $C_{\mathrm{Kr}}^{\mathrm{IG}}$ obtained with the Inverse Gaussian distribution.

\begin{tabular}{|c|c|c|}
\hline $\mathrm{N}$ & LPM's name & Expression \\
\hline 1 & Dirac (Piston Flow) & $f_{T}(t)=\delta(t-T)$ \\
& Exponential (Exponential) & $f_{T}(t)=\frac{1}{T} \exp \left(-\frac{t}{T}\right)$
\end{tabular}

Table 1: LPMs used in this study with their number of parameters N, their expression and a sketch of the associated circulation. The name referring to this LPM according to Maloszewski \& Zuber (1996) is recalled in brackets. 


\begin{tabular}{cll}
\hline \multicolumn{1}{c}{ Parameters } & Values & References \\
\hline & & \\
Potential recharge rate R $[\mathrm{mm} /$ year $]$ & 200 & (Carn, 1990; Touchard, 1999) \\
Granites conductivity $[\mathrm{m} / \mathrm{s}]$ & $10^{-11}$ & \\
Mean thickness $H_{T O T}[\mathrm{~m}]$ & 280 & (Ruelleu et al., 2010) \\
Micaschists permeability $K_{M S}[\mathrm{~m} / \mathrm{s}]$ & $5 \times 10^{-6}$ & (Leray et al., 2012) \\
Contact zone transmissivity $T_{C Z}\left[\mathrm{~m}^{2} / \mathrm{s}\right]$ & $2.2 \times 10^{-3}$ & (Le Borgne et al., 2004, 2006) \\
North 20 ${ }^{\circ}$ fault transmissivity $\left[\mathrm{m}^{2} / \mathrm{s}\right]$ & $1.1 \times 10^{-3}$ & (Le Borgne et al., 2004, 2006) \\
Porosity $\phi[\%]$ & 2.7 & (Leray et al., 2012) \\
\hline
\end{tabular}

Table 2: Parameters of the model of Plœemeur used in this study with the associated references. $H_{T O T}$ represents the mean thickness of the aquifer system composed of the micaschists and of the contact zone (see Figure 3).

\begin{tabular}{|r|r|c|c|c|c||c|c|c|c|}
\hline \multicolumn{2}{|c|}{} & \multicolumn{4}{|c||}{ Statistics on $\rho[\%]$} & \multicolumn{3}{|c|}{ Statistics on $\theta$ [years] } \\
\hline $\mathrm{N}$ & LPM considered & $\bar{\rho}$ & $\sigma(\rho)$ & $P(\rho>10 \%)$ & $\max (\rho)$ & $\bar{\theta}$ & $\sigma(\theta)$ & $\min (\theta)$ & $\max (\theta)$ \\
\hline \multirow{3}{*}{1} & Dirac & 0.0 & 0.0 & 0.0 & 0.0 & 8.9 & 4.9 & 0.6 & 21.5 \\
& Exponential & 99 & 198 & 45 & 1140 & 8.6 & 4.5 & 1.0 & 19.6 \\
\hline \multirow{3}{*}{2} & Inverse Gaussian & 1.1 & 3.3 & 4.1 & 18 & 3.2 & 1.8 & 0.2 & 10.7 \\
& Shifted Exponential & 3.8 & 3.6 & 5.5 & 16 & 3.3 & 1.7 & 0.6 & 8.4 \\
& Oniform & 3.7 & 6.4 & 12 & 38 & 3.7 & 1.8 & 0.0 & 8.9 \\
\hline \multirow{3}{*}{3} & Shifted Inverse Gaussian & 2.0 & 3.6 & 5.5 & 20 & 2.4 & 1.6 & 0.1 & 6.6 \\
& Sum of Diracs & 0.01 & 0.03 & 0.0 & 0.04 & 4.9 & 3.1 & 0.0 & 16.4 \\
\hline
\end{tabular}

Table 3: Statistics on the residual $\rho$ (equation 7) and on the predictive accuracy $\theta$ (equation 8) obtained with the calibrations carried on 73 sampling zones for the LPMs. $N$ is the number of the parameters of the LPM considered, $P(\rho>10 \%)$ represents the percentage of sampling zones where $\rho$ is superior to $10 \%$. 


\section{Highlights}

- Analysis of Transit Time Distributions (TTDs) on a crystalline aquifer model.

- Prediction of renewal times of the aquifer from environmental tracers.

- High predictive capacities of lumped models with two parameters requiring two tracers.

- Shape of the TTDs is not critical beyond the first 2 moments of the distribution. ! 